\title{
COMPARING TWO APPROACHES ON THE ESTIMATIVE ANISOTROPIC PARAMETERS FROM WELL LOGS: AN APPLICATION ON THE NORNE FIELD DATASET
}

\author{
Caio Leandro Perdigão Castro ${ }^{1}$, José Jadsom Sampaio de Figueiredo ${ }^{1,2}$ \\ and Isadora Augusta Soares de Macedo $0^{1,2}$
}

\begin{abstract}
Estimating the elastic properties of the rocks in the subsurface is a task with many challenges. The main goal of this work is to estimate the Thomsen anisotropic parameters from the inversion of elastic stiffness coefficients using data from five wells of the Norne Field, located at Norway. We compare the results of these parameters with the Backus average, using Li's empirical method. Further, aspect ratio and crack density are calculated from the results of the elastic stiffness coefficients. It is considered a transversely isotropic medium. The results from the two methods showed similarities in estimating anisotropic parameters, aspect ratio and fracture density. The anisotropy of the study area is weak with some regions with moderate anisotropy. Some patterns suggest the possibility of calculating the anisotropic parameters for the adjacent wells and interpolate values for use in seismic processing
\end{abstract}

Keywords: transversally isotropic medium, well logs, Thomsen parameters, Backus average.

RESUMO. Estimar as propriedades elásticas das rochas em subsurperfície é uma tarefa com muitos desafios. 0 principal objetivo deste trabalho é estimar os parâmetros de anisotropia de Thomsen a partir da inversão dos coeficientes de rigidez elástica, utilizando dados de cinco diferentes poços do campo de Norne, Iocalizado na Noruega. Comparamos os resultados obtidos para esses parâmetros com a média de Backus, usando o método empírico de Li. Em seguida, a razão de aspecto e a densidade de fratura foram calculadas a partir dos resultados dos coeficientes de rigidez elástica. 0 meio transversalmente isotrópico é considerado neste trabalho. Os resultados obtidos a partir dos dois métodos mostraram similaridades na estimativa dos parâmetros de anisotropia, razão de aspecto e densidade de fratura. A anisotropia da área de estudo é fraca com algumas regiões de anisotropia moderada. Alguns padrões encontrados sugerem a possibilidade de calcular os parâmetros de anisotropia para os poços vizinhos e interpolá-los para uso futuro no processamento sísmico.

Palavras-chave: meios transversalmente isotrópicos, perfis de poços, parâmetros de Thomsen, média de Backus.

\footnotetext{
${ }^{1}$ Universidade Federal do Pará (UFPA), Faculty of Geophysics, Petrophysics and Rock Physics Laboratory - Prof. Dr. Om Prakash Verma, Belém, PA, Brazil - E-mails: caio.geofisica@gmail.com, jadsomjose@gmail.com, isadora.s.macedo@gmail.com

${ }^{2}$ National Institute of Petroleum Geophysics (INCT-GP), Brazil.
} 


\section{INTRODUCTION}

Anisotropy is the variation of a determined physical property according to the direction of investigation. In shales, for instance, many factors may produce anisotropy. Within such, special attention is given to the alignment of clay plates, organic matter, stresses and aligned fractures or fissures within an isotropic rock (Shearer, 2009). As layers present preferential orientation, reservoir permeability is affected by such orientation, thus the routes of oil flow may be determined, helping to improve petrol production. This is one of the reasons anisotropy is taken into consideration in seismic context (Ikelle \& Amundsen, 2005).

Due to the presence of shales in many sedimentary basins, understanding how seismic waves behave in this type of rock is fundamental. Currently, the comprehension of elastic properties of shales is insufficient, for it is based on a limited amount of observations (Ougier-Simonin et al., 2009). Determine such properties means to find the elastic stiffness tensor. Since the elastic constants of the medium are known, propagating characteristics of elastic waves going through it may be modeled (Douma, 1988). Data from wells are sources that allow the reconstruction of the elastic stiffness tensor.

In the present work we utilize a procedure for estimating the anisotropic parameters from well measures. Specifically, the gamma-ray profile will be utilized to calculate the IGR (radioactivity index) and the volume of the shale, and the sonic logs will be converted into velocity logs of $P$ and $S$ waves. We will relate Thomsen anisotropic parameters to matrix coefficients of elastic stiffness, fracture density and aspect ratio, obtained by two methods, Li (2006) and Backus (1962).

We will apply these methods on five wells located in the Norne Field, Norway and based on them, we verify whether there is consistency in the estimative of anisotropic parameters for both aforementioned methods.

\section{THEORETICAL BASES AND METHOD}

\section{Transversally isotropic medium}

Transversely isotropic media are thus named because any direction normal to the axis of symmetry possesses the same properties. The axis of symmetry is associated to bedding and stress regions. A VTI medium may be found in sandstone-shale layers and the velocity of $\mathrm{P}$ waves differ when propagated along the axis of symmetry $(z)$ and along the direction normal to this (plane $(x, y)$ ).

For $\mathrm{S}$ waves, if they propagate in parallel to the axis of symmetry, the compounds $S_{V}$ and $S_{H}$ are equal. Since there are two perpendicular coexisting $S$ waves, the bi-refrangibility phenomenon of wave occurs, and $S_{V}$ is different from $S_{H}$. The elastic stiffness tensor of a VTI medium is given by:

$$
\mathrm{C}_{\mathrm{ij}}^{\mathrm{VTI}}=\left[\begin{array}{cccccc}
C_{11} & C_{11}-2 C_{66} & C_{13} & 0 & 0 & 0 \\
C_{11}-2 C_{66} & C_{11} & C_{13} & 0 & 0 & 0 \\
C_{13} & C_{13} & C_{33} & 0 & 0 & 0 \\
0 & 0 & 0 & C_{55} & 0 & 0 \\
0 & 0 & 0 & 0 & C_{55} & 0 \\
0 & 0 & 0 & 0 & 0 & C_{66}
\end{array}\right]
$$

The constants $C_{11}$ (horizontal $\mathrm{P}$ wave) and $C_{33}$ (vertical $\mathrm{P}$ wave) as well as $C_{55}$ (vertical $S_{V}$ ) and $C_{66}$ (horizontal $S_{H}$ ) differ from one another. For $S$ waves that propagate along the $z$-axis, vertical and horizontal components are equal $\left(C_{44}=C_{55}\right)$.

\section{Anisotropic Parameters}

The tensor 1 shows that a transversely isotropic medium requires five independent elastic constants for its characterization. Thomsen (1986) presented a set of anisotropic constants to describe VTI media. Such constants are given through velocities of compressional and shear waves perpendicular to bedding plane, denoted by $V_{P_{0}}, V_{S_{0}}$, respectively, and by three non-dimensional anisotropic parameters (Eqs. 2 to 6), where $\varepsilon$ and $\gamma$ denote the fractional difference between wave velocities, fast and slow, of $\mathrm{P}$ and $\mathrm{S}$ waves respectively, and $\delta$ is related to the velocity variation of the $P$ wave with polar angles, related to the axis of symmetry of the medium (Ikelle \& Amundsen, 2005; Zhu et al., 2004).

$$
\begin{gathered}
V_{P_{0}}=\sqrt{\frac{C_{33}}{\rho}}, \\
V_{S_{0}}=\sqrt{\frac{C_{55}}{\rho}}, \\
\varepsilon=\frac{C_{11}-C_{33}}{2 C_{33}}, \\
\gamma=\frac{C_{66}-C_{55}}{2 C_{55}}, \\
\delta=\frac{\left(C_{13}+C_{55}\right)^{2}-\left(C_{33}-C_{55}\right)^{2}}{2 C_{33}\left(C_{33}-C_{55}\right)} .
\end{gathered}
$$


These parameters measure anisotropy for a VTI medium, thus describing the variation of velocity of compressional and shear waves in function of the polar angle to the axis of symmetry (Gurevich, 1999). It is possible to determine the $C_{33}$ and $C_{55}$ coefficients, applying the inversion of Eqs. (2) and (3), utilizing the sonic and density logs. In the absence of plugs to get the remaining coefficients, an alternative is to obtain the Thomsen parameters through empiric methods, which have as entry the velocity profiles converted through the sonic profile and the shale volume log.

\section{Density and aspect ratio of fractures and fissures}

Schoenberg \& Douma (1988) defined a relation between three parameters that includes; density of fractures, aspect ratio and elastic stiffness, to describe a fractured medium. The relation between the aspect ratio $(\alpha)$ and the elastic-stiffness coefficients can be written as:

$$
\alpha=\frac{K_{f}}{\pi \cdot C_{44} H},
$$

and

$$
H=\frac{8\left(2 C_{11}+C_{13}\right)\left(C_{66}-C_{44}\right)}{C_{44}\left(2 C_{66}-C_{33}+C_{13}\right)}-\frac{C_{33}+C_{13}}{2 C_{33}},
$$

and

$$
K_{f}=\left(\frac{S_{w}}{K_{w}}+\frac{1-S_{w}}{K_{h c}}\right)^{-1},
$$

where $K_{f}$ is the Bulk modulus of the fluid kept in the fracture or fissure, $S_{w}$ is the water saturation and $K_{w}$ and $K_{h c}$ are the Bulk modulus of the water and hydrocarbon, respectively. A way to calculate the fracture density $(e)$ is by Schoenberg's tangential complacency $\left(E_{T}\right)$, given by the expression:

$$
E_{T}=\frac{16 e}{3\left(3-2 \Gamma_{b}\right)}
$$

in which

$$
\Gamma_{b}=\left(\frac{V_{S}}{V_{P}}\right)^{2},
$$

and $V_{P}$ and $V_{S}$ are the $\mathrm{P}$ and $\mathrm{S}$-wave velocities normal to bedding plane. If the $\gamma$ parameter is known, it is possible to estimate $E_{T}$ by the relation:

$$
\gamma=\frac{E_{T}}{2},
$$

and the fracture density can be found by substituting Eq. (12) in Eq. (10).

Based on these equations, obtaining the five Thomsen parameters to describe an anisotropic medium with data obtained in well logs, is a mean to determine the fracture density and the aspect ratio quantitatively.

\section{Geology of the Norne Field}

The five well logs that were investigated in this work have information from different geologic formations of the Norne Field. This field gathers many other groups of which two are more important: Fangst group and Båt group (Statoil, 2001).

\section{- Fangst group}

The Fangst group is composed by the Garn, Not and lle formations. The Garn formation is composed by sandstones with quartz grains ranging from bright to dark brown, presenting in some cases a calcite matrix. The grains are sub-rounded and well sorted. It also contains limestones and claystones. The transition between the Garn and Not formations contains the first silty sand layers. The Not formation is composed by gray/dark brown shales, it also has traces of micas and carbon materials. The lle formation is composed of sandstones with quartz grains with color ranging from bright to brown. The grains are thinner, moderated to well sorted sub-rounded. Occasionally presents some limestones and interbedded shales.

\section{- Båt group}

The Båt group is represented by the Tofte, Tilje and Åre formations. The formation Tofte consists of interbedded shale and sandstones, with limestones occurring occasionally. The grains are medium to thin size and vary on moderate to well sorted. The Tilje formation contains sandstones and shales with some limestone laminations. Some highly carbonous layers are observed often. The grainsize range from very thin to medium, presenting, eventually, thick to very thick granulation. The Åre formation consists on silty sandstones to interbedded mudstones with some shale layers and limestone lamination. The sands are composed by quartz with granulation ranging from very thin to thin. Moderate and sub-angular selection.

\section{Shale volume calculation}

Shales are more radioactive than sandstones and carbonates. It happens due to the presence of $K^{40}$ in its composition. Thus, the gamma ray log can be used to calculate the shale volume of a specific formation. Different authors presented non-linear empiric or experimental equations to calculate the shale volume, in which some other factors, such as the rock's age, is considered. These expressions require the establishment of the radioactive index 
Table 1 - Depths of the geological formations for the five wells.

\begin{tabular}{|l|l|l|l|l|l|}
\hline Formation & B4AH & B4H & C1H & C3H & D4H \\
\hline Garn & $3196-3328.5 \mathrm{~m}$ & $2573.5-2605.5 \mathrm{~m}$ & $2911-2946 \mathrm{~m}$ & $3348-3377.4 \mathrm{~m}$ & $2714-2756 \mathrm{~m}$ \\
\hline Not & $3328.5-3368 \mathrm{~m}$ & $2605.5-2614 \mathrm{~m}$ & $2946-2953.5 \mathrm{~m}$ & $3377.4-3388 \mathrm{~m}$ & $2756-2766 \mathrm{~m}$ \\
\hline Ile & $3368-3602.5 \mathrm{~m}$ & $2614-2658 \mathrm{~m}$ & $2953.5-2991 \mathrm{~m}$ & $3388-3440 \mathrm{~m}$ & $2766-2821.5 \mathrm{~m}$ \\
\hline Tofte & $3602.5-3741 \mathrm{~m}$ & $2658-2720 \mathrm{~m}$ & $2991-3055 \mathrm{~m}$ & $3440-3503 \mathrm{~m}$ & $2821.5-2903 \mathrm{~m}$ \\
\hline Tilje & $3741-3888 \mathrm{~m}$ & $2720-2838.5 \mathrm{~m}$ & $3055-3146.5 \mathrm{~m}$ & $3503-3634 \mathrm{~m}$ & $2903-3039 \mathrm{~m}$ \\
\hline Åre & $3888-3900 \mathrm{~m}$ & $2838.5-2914 \mathrm{~m}$ & $3146.5-3297 \mathrm{~m}$ & $3634-3754.9 \mathrm{~m}$ & $3039-3120.4 \mathrm{~m}$ \\
\hline
\end{tabular}

$\left(I_{G R}\right)$ to calculate the shale volume (Nery, 2013) which is given by

$$
V_{s h}=0.33 \times\left(2^{2 I_{G R}}-1\right),
$$

where

$$
I_{G R}=\frac{G R_{l o g}-G R_{\min }}{G R_{\max }-G R_{\min }} .
$$

The Eq. (12) was proposed by Larionov (1969) for ancient rocks. As the geologic formations under analysis date from the Jurassic period, we will utilize this equation as a correction factor.

\section{Thomsen parameters calculation}

\section{Empiric method}

Li (2006) proposed a method to estimate $\varepsilon, \gamma$ and $\delta$ by the following relations:

$$
\begin{gathered}
\varepsilon=\frac{0.6 * V_{\text {sh }} *\left(V_{P 0}-V_{P_{\text {water }}}\right)}{V_{P_{\text {quartz }}}-V_{P_{\text {water }}}-2.65 * V_{\text {sh }}}, \\
\gamma=\frac{0.67 * V_{\text {sh }} * V_{S 0}}{V_{\text {Squartz }}-2.29 * V_{\text {sh }}}, \\
\delta=0.32 \varepsilon,
\end{gathered}
$$

where $V_{P 0}$ and $V_{S 0}$ are the compressional and shear wave velocity logs that propagate perpendicular to the bedding plane, $V_{s h}$ is the shale volume, $V_{P \text { water }}$ is an approximation of the compressional wave velocity to the critical porosity, $V_{P \text { quart }}$ is the velocity of the $\mathrm{P}$ wave in quartz and $V_{\text {Squartz }}$ is the velocity of the $S$ wave in quartz. The constants used in Eqs. (15) and (16) are: $V_{P_{\text {water }}}=1.5 \mathrm{~km} / \mathrm{s}, V_{\text {Pquartz }}=6.05 \mathrm{~km} / \mathrm{s}$ and $V_{\text {Squartz }}=4.09 \mathrm{~km} / \mathrm{s}$.

\section{Backus average}

The calculation used to obtain the properties of an effective medium utilizing the Backus average, consists on first obtaining the elastic stiffness tensor utilizing the $P$ and $S$ wave logs and the density log, subsequently applying the averages (Kumar, 2013). We applied the three Thomsen anisotropic parameters of Viking Graben field (North sea), to find the tensor coefficients of Eq. (1). Table 2 shows the rock's properties (sandstone and shale) used in this study.

Table 2 - Anisotropic parameters to calculate the Backus average. We used this values based on Kumar (2013).

\begin{tabular}{|l|c|c|c|}
\hline Lithology & $\varepsilon$ & $\gamma$ & $\delta$ \\
\hline Shale & 0.23 & 0.38 & 0.1 \\
\hline Sandstone & 0 & 0 & 0 \\
\hline
\end{tabular}

Different studies have shown that shales are intrinsically anisotropic (Johnston \& Christensen, 1995), while sandstones are mostly isotropic. Based in this assumptions and using the local informations of Table 2, we can write the Thomsen parameters as function of shale fraction volume by

$$
\begin{gathered}
\varepsilon=0.23 V_{s h}, \\
\gamma=0.38 V_{s h}, \\
\delta=0.1 V_{s h} .
\end{gathered}
$$

The system of equations above shows that when the medium is totally composed by clean sandstone $\left(V_{s h}=0\right)$, the 
effective medium is isotropic, and when it is composed totally by shale $\left(V_{s h}=1\right)$, the effective medium is VTI, as expected. The Backus average is used in models of thin stratified layers, with the objective of represent individual homogeneous layers (Mavko et al., 2009). The thickness used for the average calculation in this study was $20 \mathrm{~m}$, however it can assume other values (Liner \& Fei, 2006). This average for each rock layer along a well is given by:

$$
\begin{gathered}
C_{33}^{e}=\left\langle\frac{1}{C_{33}}\right\rangle^{-1}, \\
C_{44}^{e}=C_{55}^{e}=\left\langle\frac{1}{C_{44}}\right\rangle^{-1}, \\
C_{13}^{e}=C_{23}^{e}=\left\langle\frac{C_{13}}{C_{33}}\right\rangle\left\langle\frac{1}{C_{33}}\right\rangle^{-1}, \\
C_{66}^{e}=\left\langle C_{66}\right\rangle, \\
+\left\langle\frac{C_{13}}{C_{33}}\right\rangle^{2}\left\langle\frac{1}{C_{33}}\right\rangle^{-1}-\left\langle\frac{C_{13}^{2}}{C_{33}}\right\rangle, \\
C_{12}^{e}=\left\langle C_{12}\right\rangle+\left\langle\frac{C_{13}}{C_{33}}\right\rangle^{2}\left\langle\frac{1}{C_{33}}\right\rangle^{-1}-\left\langle\frac{C_{13}^{2}}{C_{33}}\right\rangle= \\
=C_{11}^{e}-2 C_{66}^{e} .
\end{gathered}
$$
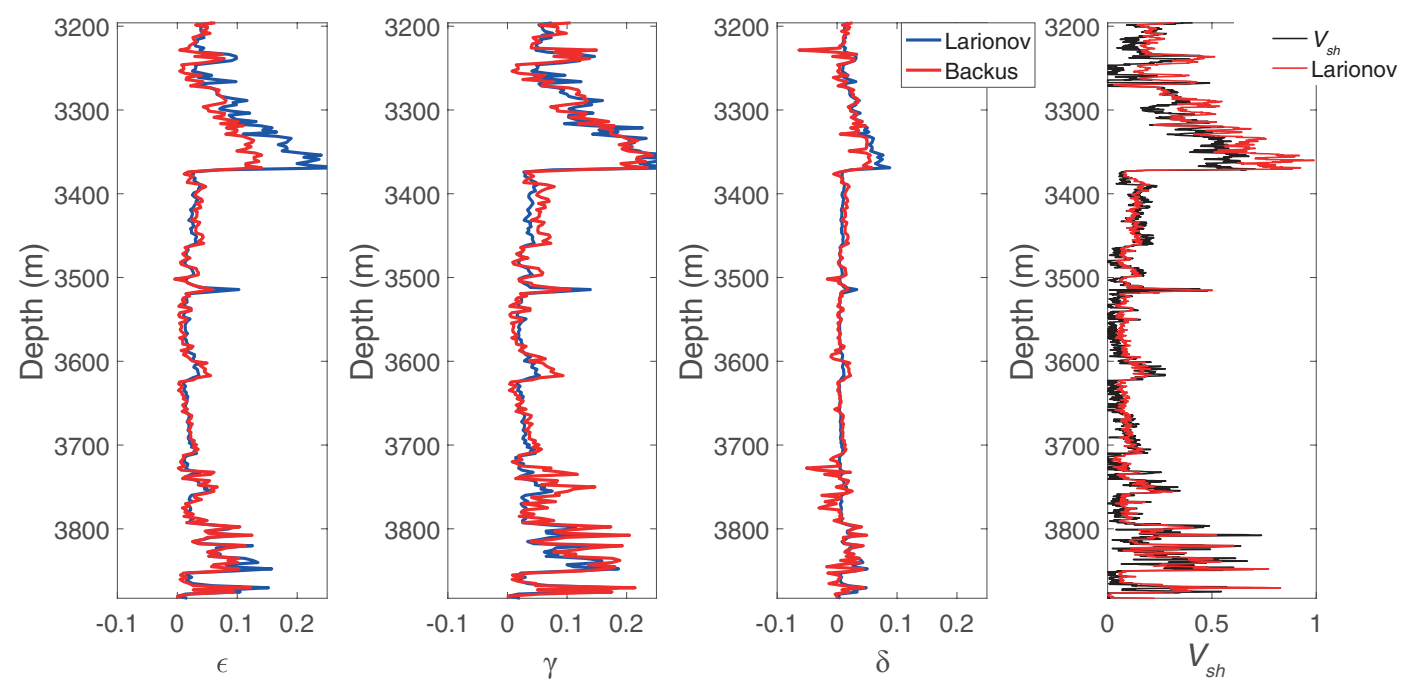

Figure 1 - Anisotropic parameters and shale volume logs for the well B4AH.

\section{RESULTS}

\section{Anisotropic parameters}

As observed previously, a VTI medium presents a vertical symmetry axis, where there is variation on the waves velocity according to the direction of investigation. Thus, the Thomsen anisotropic parameters might be calculated, and by them, the elastic stiffness coefficients can be inverted. Considering this medium for the studied wells and utilizing the methodologies proposed by Li (2006) and Backus (1962), we obtain the following results for the anisotropic parameters for each well observed on the Figures 1,2,3,4 and 5 .

There are two different colors on the columns of the figures above. The red curve is the result for a VTI medium utilizing Backus average (Backus, 1962), and the blue curve is utilizing Li (2006). The first three columns, from left to right, show the Thomsen parameters, the fourth column shows the relation between the shale volume log, and its equivalent, calculated through Larionov (1969), for old rocks. It is notable the relation between the anisotopic parameters with the shale volume log. The highest values of anisotropy are located at the same depths of the highest values of shale volume. This analysis was already expected, because we know that shales are intrinsically anisotropic. It is possible to notice that the absolute values of the anisotropic parameters $\varepsilon, \gamma$ and $\delta$ vary from 0 to 0.2 at most part of the log, eventually exceeding its maximum value, which indicates weak to moderate anisotropy (Thomsen, 1986). 

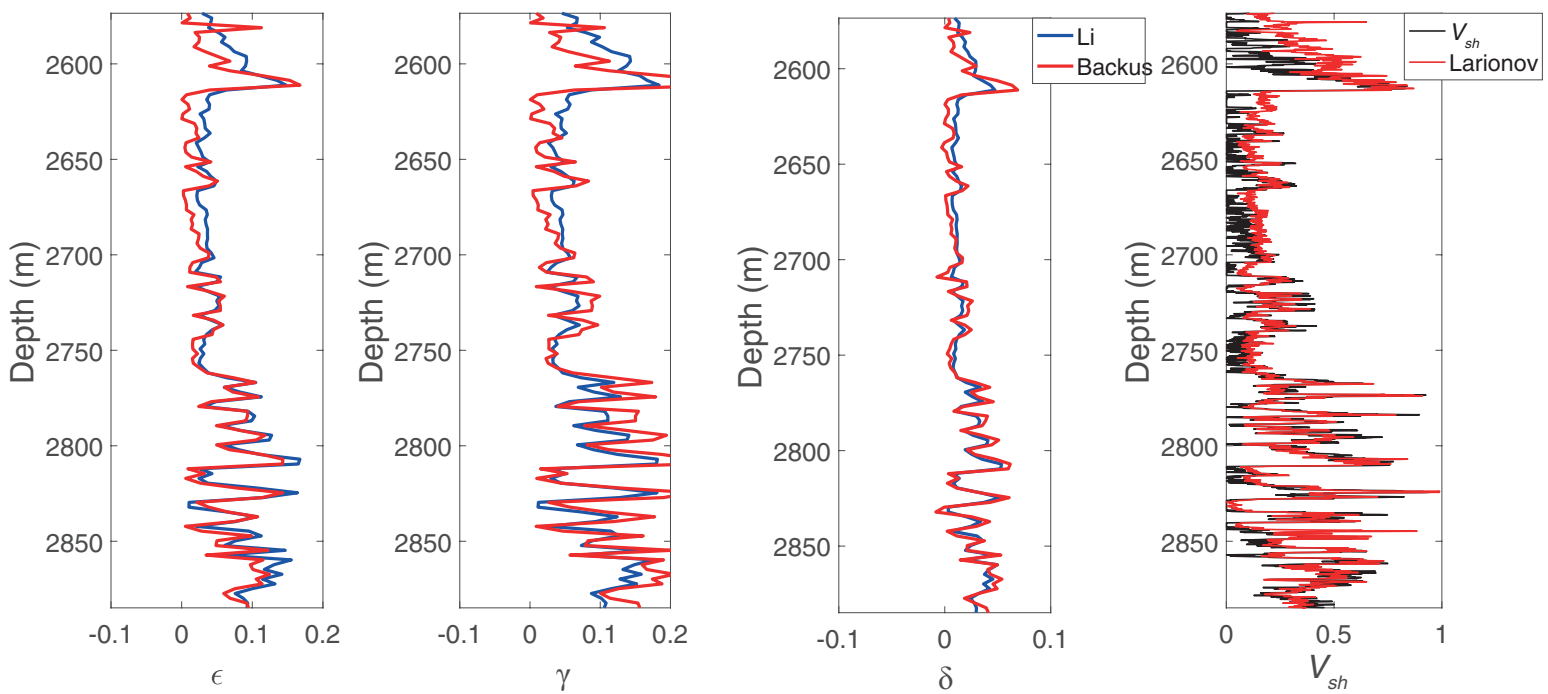

Figure 2 - Anisotropic parameters and shale volume logs for the well B4H.
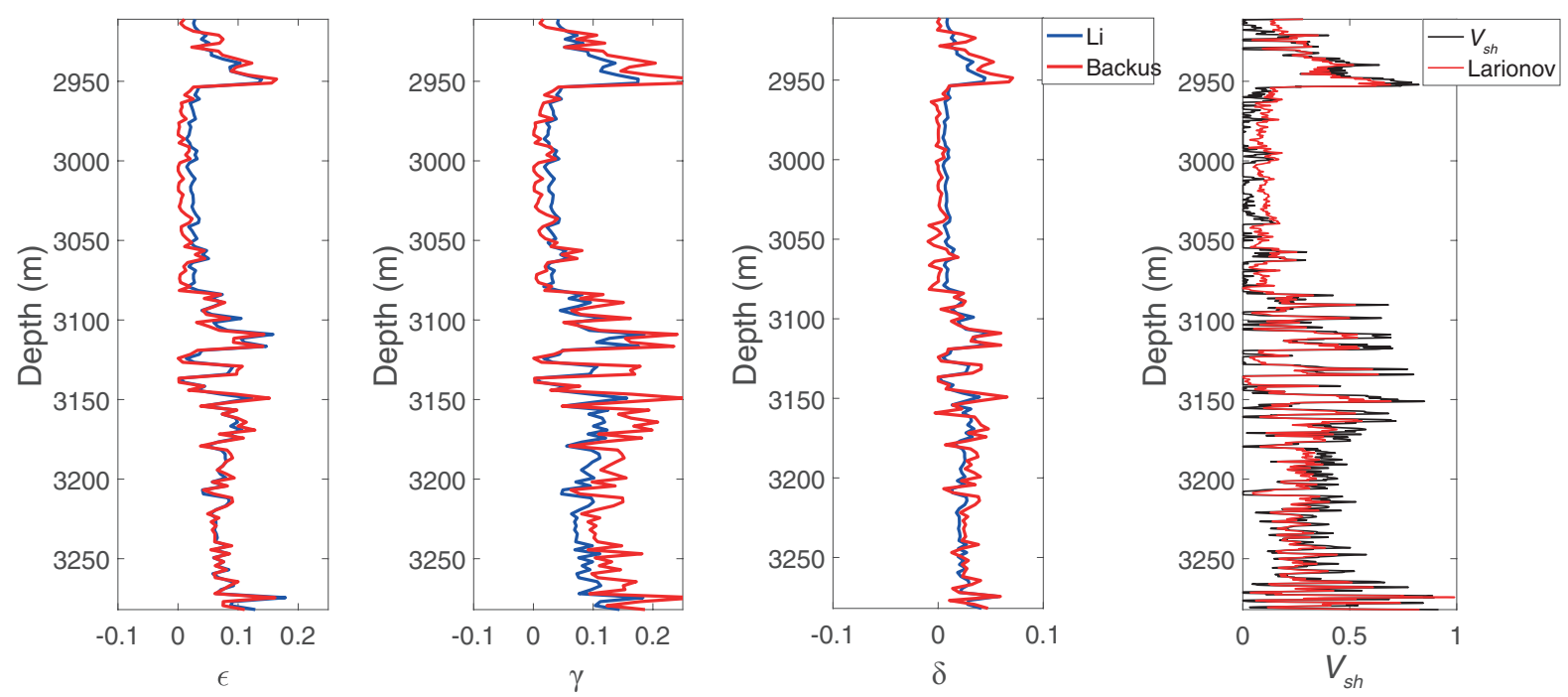

Figure 3 - Anisotropic parameters and shale volume logs for the well $\mathrm{C} 1 \mathrm{H}$.

In all logs, the curves generated from the two methodologies present similar behavior. Differences appear in different parts of the curves. On well B4AH, for example, the obtained values for parameter $\varepsilon$, between depths of $3300 \mathrm{~m}$ and near $3400 \mathrm{~m}$, utilizing $\mathrm{Li}$ (2006), present higher values than those obtained by Backus (1962). On well B4H the values for $\varepsilon, \gamma$ present better adjustment with the depth increase. For well $\mathrm{C} 1 \mathrm{H}$ the curves adjust well for $\varepsilon$ and $\sigma$ while for $\gamma$, between depths $3050 \mathrm{~m}$ until the end of the log, Backus (1962) presents higher values than Li (2006). On well $\mathrm{C} 3 \mathrm{H}$, we notice the same characteristic observed on well $\mathrm{C} 1 \mathrm{H}$, where the values of parameter $\gamma$ obtained by Backus are greater than $\mathrm{Li}$, between depths $3550 \mathrm{~m}$ until the end of the log. Finally, it is noticeable that well D4H presents the smaller adjustments between the two curves, mainly the curve of parameter $\gamma$ obtained utilizing Backus, which appears to be dislocated to the right when compared to the one obtained by Li (2006).

\section{Fracture density and aspect ratio}

With the results presented previously, it is also possible to estimate the fracture density of the medium and the aspect ratio 

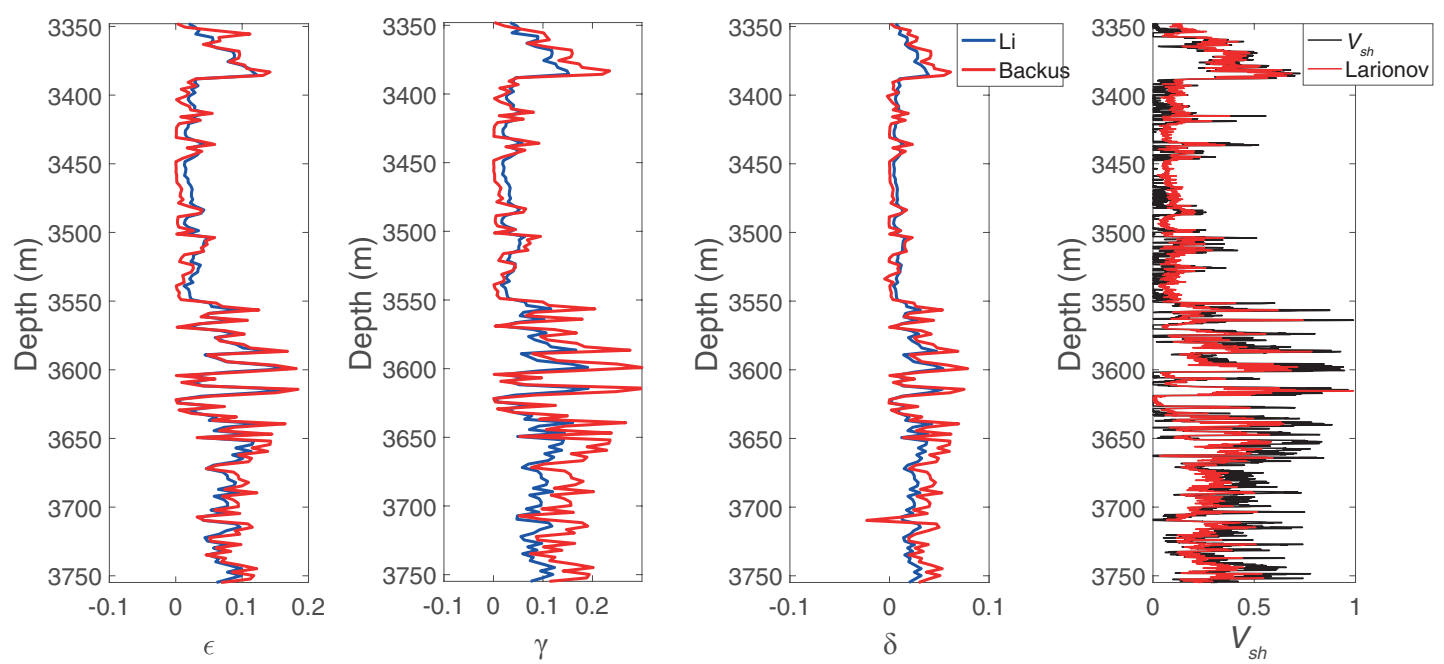

Figure 4 - Anisotropic parameters and shale volume logs for the well C3H.
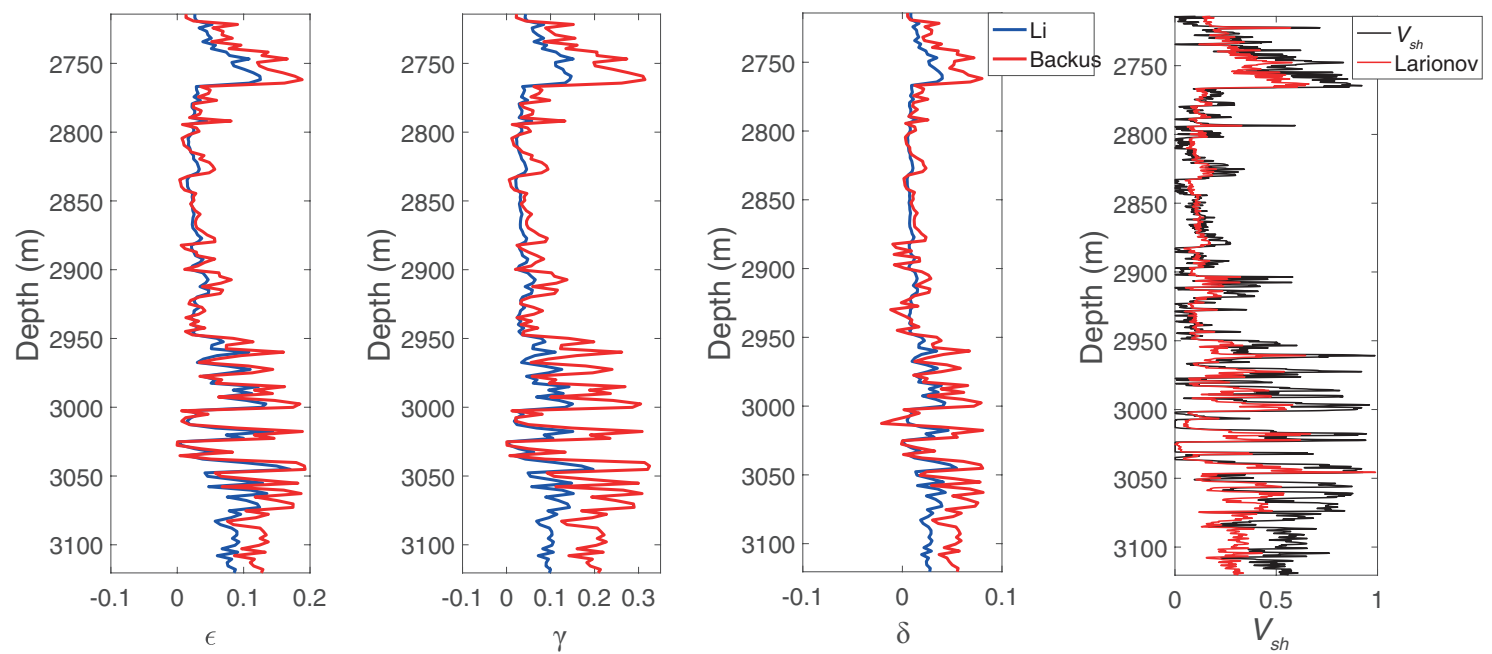

Figure $\mathbf{5}$ - Anisotropic parameters and shale volume logs for the well D4H.

through Eqs. (7) and (10). For that, the values utilized in Eq. (9) were the water saturation profiles, and the values for the Bulk modulus of water and hydrocarbon were $2.2 \mathrm{GPa}$ and $0.37 \mathrm{GPa}$, respectively. Figures 7, 8, 9, 10 and 11 show the fracture density and aspect ratio for each well.

Analyzing the figures above, it is notable that there is a fine adjustment between the curves for the aspect ratio in all wells. For the fracture density, the obtained values by both methodologies present similar bahaviour, although dislocated through the entire profile. The fractures density is directly related to parameter $\gamma$ through Eqs. (10) and (12), and analyzing the profiles of this parameter, it is noticeable that the displacements are around $5 \%$ in some regions of the first four wells. On well $\mathrm{D} 4 \mathrm{H}$, the displacement overcome $10 \%$ in some regions.

\section{DISCUSSIONS}

For the adimensional anisotropic parameters logs, there are two intervals of depth where the highest values occur. The first one is located at the upper part of the profiles.

Consulting Table 1, it is possible to infer that those values are associated with Not formation, composed mainly by shales, which are intrinsically anisotropic. The other lower half of the 


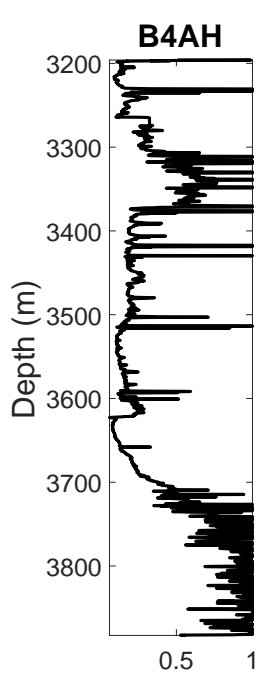

Sw

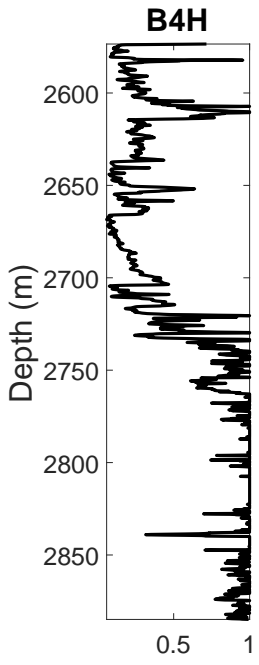

Sw

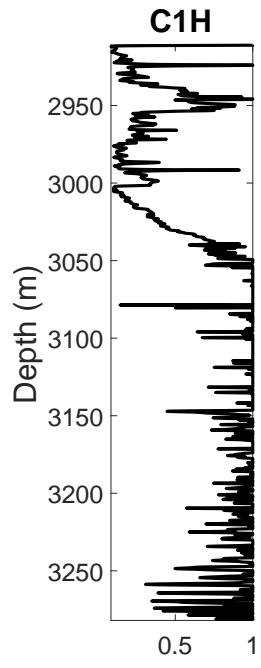

Sw

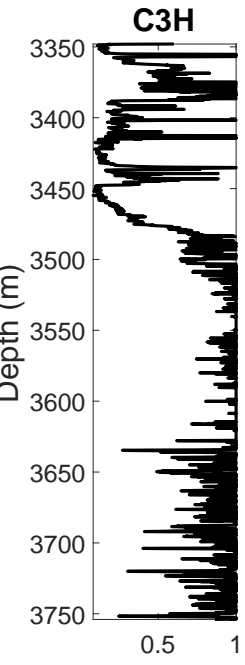

Sw

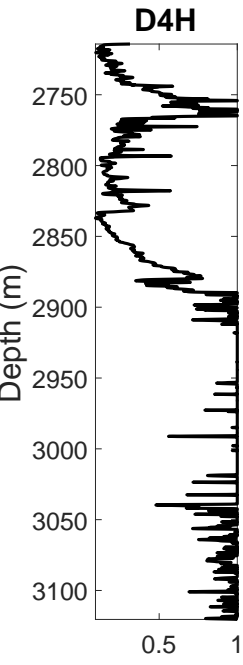

Sw

Figure 6 - Water saturation logs for all the five wells studied.
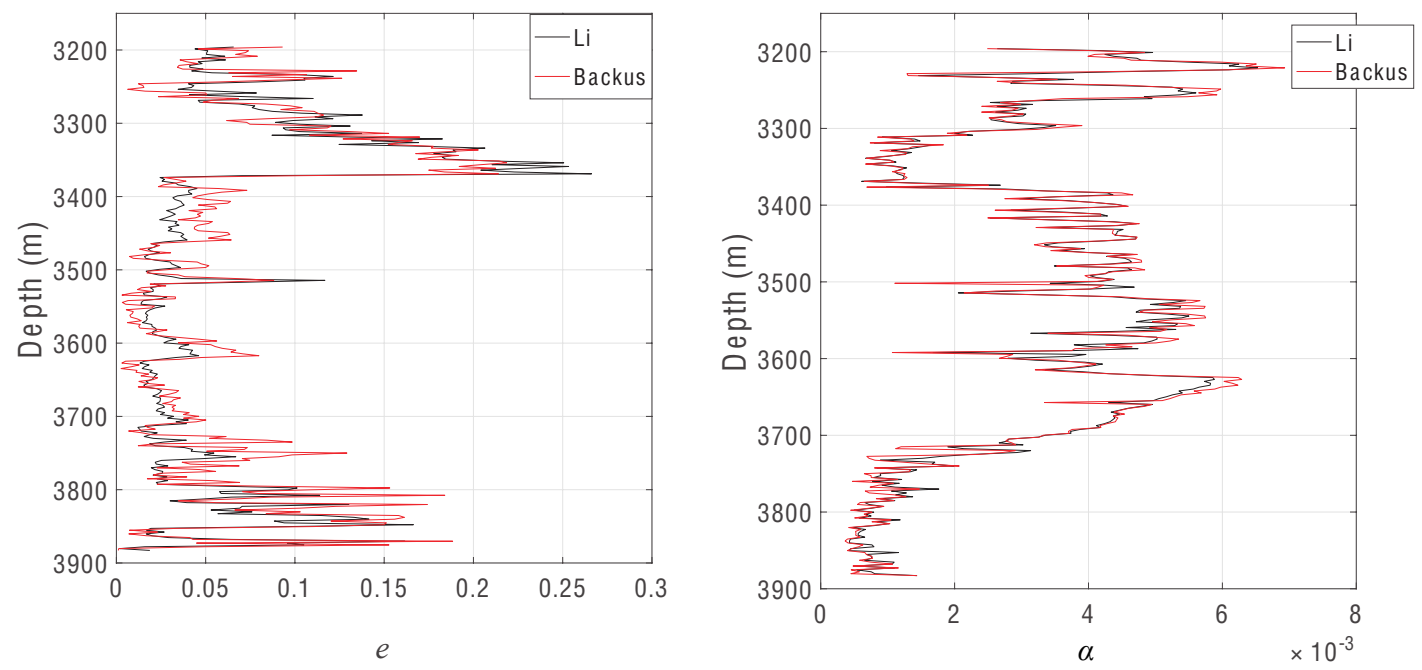

Figure 7 - Fracture density and aspect ratio logs for the well B4AH.

profiles, correspond to Tilje and Åre formations, which also present shale in their composition. There is a correspondence between the higher values of anisotropic parameters, not only with the shale volume, but also with the $\mathrm{P}$ and $\mathrm{S}$ wave velocity profiles. The highest points of $\varepsilon$ parameter corresponds to higher fluctuations of the values of P-wave velocity, while higher fluctuations of the S-wave profile, correspond to the higher values of the $\gamma$ parameter log.

Figure 12 shows three bar graphs with the average values of parameters $\varepsilon, \gamma$ and $\delta$ for each formation for all wells using
Li methodology. The first well, B4AH, is the only one to present values a little bit higher than others. Not formation is the one presenting the highest anisotropy with values ranging between 0.1 and 0.2 , followed by Åre formation with values up to 0.1 for parameter $\varepsilon$ and a little higher than 0.1 for $\gamma$. It is noticeable that the values of $\gamma$ are higher in all wells. That means $\mathrm{S}$-waves are more sensible to anisotropy than $\mathrm{P}$ - waves on this field. On well $\mathrm{B} 4 \mathrm{AH}$, it is observable that $\varepsilon=\delta$, indicating elliptical anisotropy on that proximity. Ile and Tofte formations are the ones presenting the lower anisotropy. 

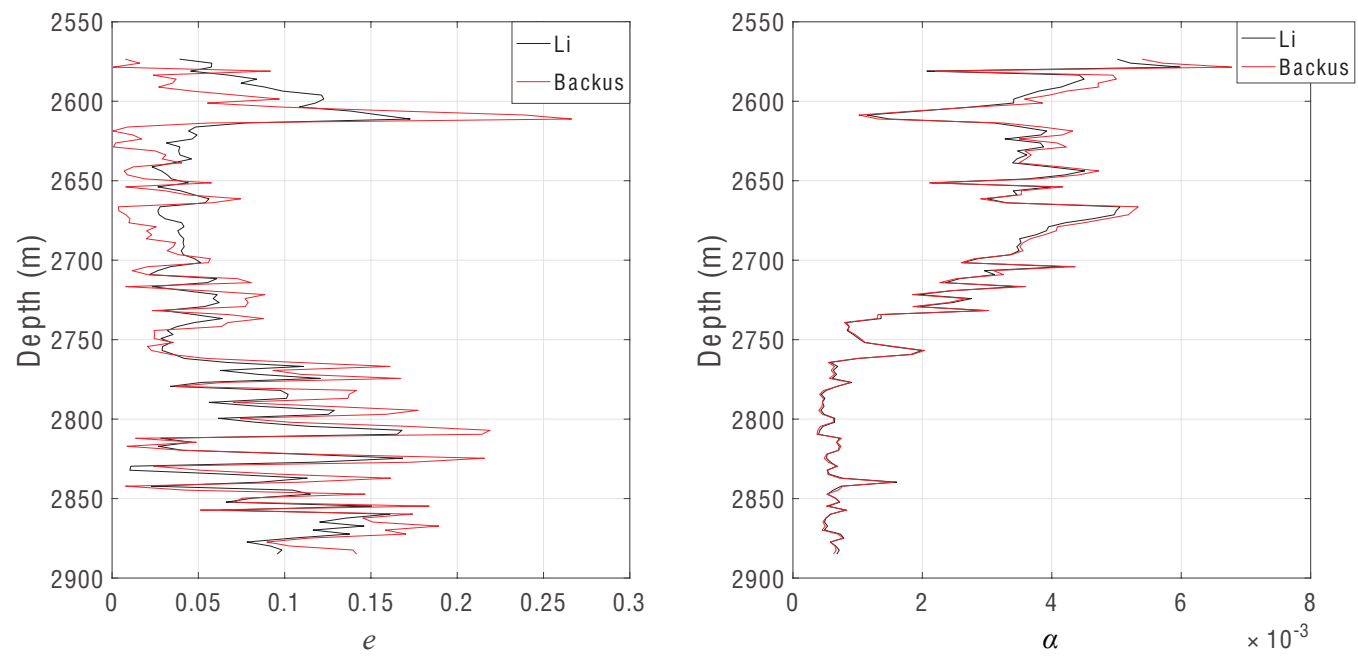

Figure 8 - Fracture density and aspect ratio logs for the well B4H.
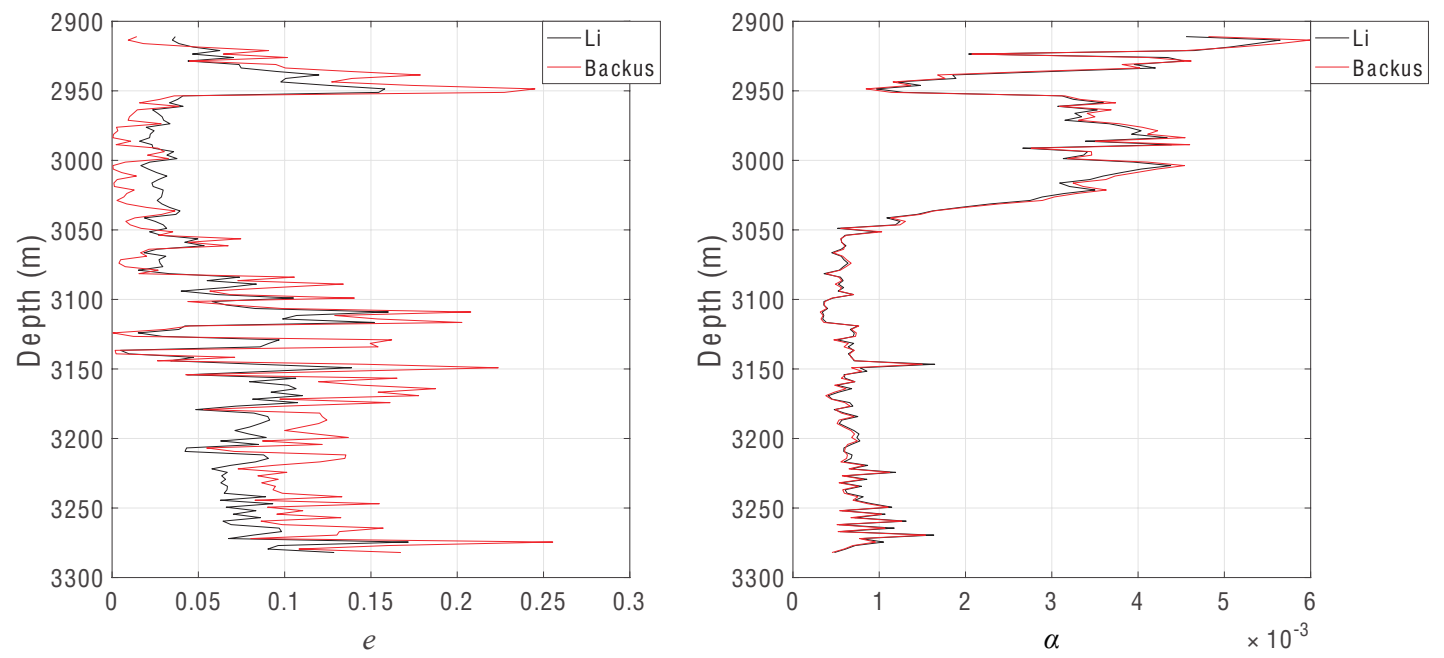

Figure 9 - Fracture density and aspect ratio logs for the well $\mathrm{C} 1 \mathrm{H}$.

Most part of the profiles shows a weak anisotropy, with the exception of the local limits and the values presented at depths correspondent to Not, Tilje and Åre formations. The values of the calculated parameters show some variations for each well, but the general characteristic is the presence of an isotropic section below Not formation with a few local effects in all profiles. The elastic stiffness constants are related to the calculated anisotropic parameters.

The highest values of $C_{i j}$ are located where occur the highest values for parameters $\delta, \varepsilon$ and $\gamma$. The log values of the anisotropic parameters are greater or equal to zero, indicating that the wave velocities that propagate perpendicular to the symmetry axis are higher than the ones that propagate parallel to this axis. Figure 13 shows three bar graphs with the average values for fracture density and aspect ratio for each formation from all wells. It is noticeable that the fracture density and aspect ratio show an inverse behavior.

The highest values of fracture density are located on the sections where there are the greatest shale volume values, the maximum fluctuations of the values from $P$ and $S$ wave velocities, the maximum fluctuations of water saturation values, and consequently maximum fluctuations on anisotropic parameters values. The lower values occur on the aspect ratio. The maximum values of fracture density reach $15 \%$ in a few parts of the curve 

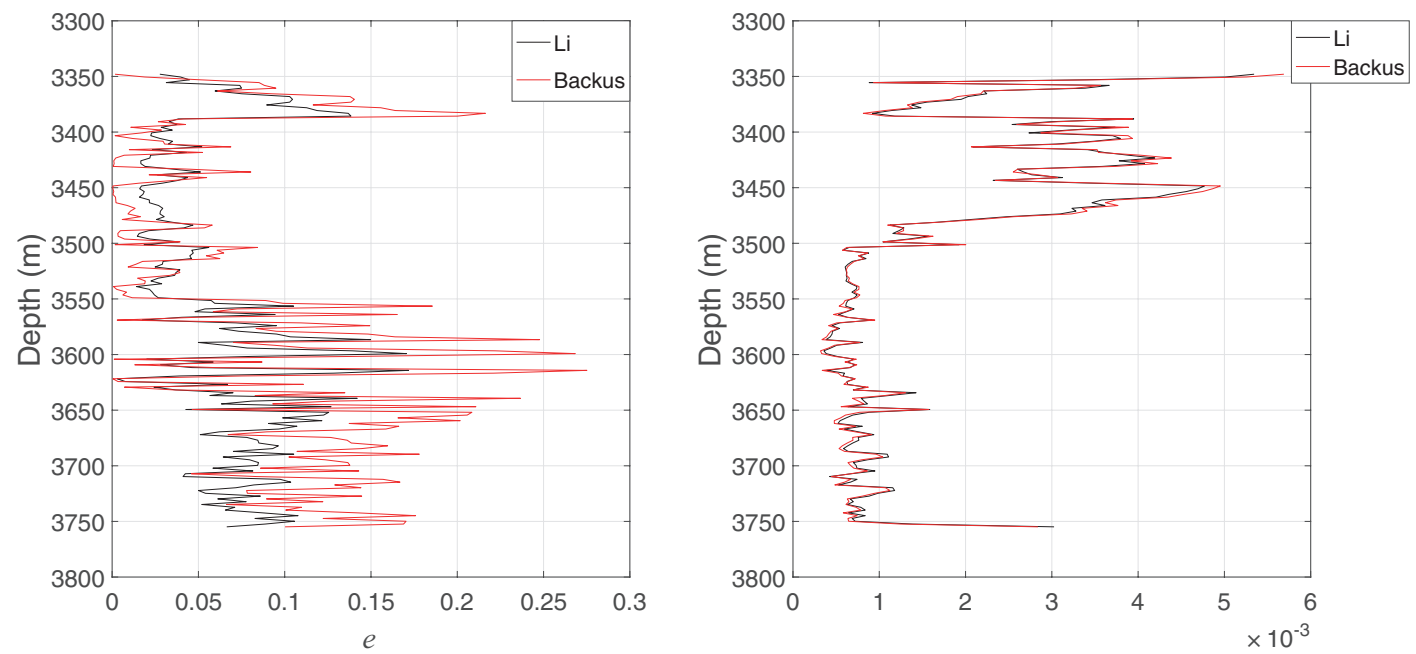

Figure 10 - Fracture density and aspect ratio logs for the well $\mathrm{C} 3 \mathrm{H}$
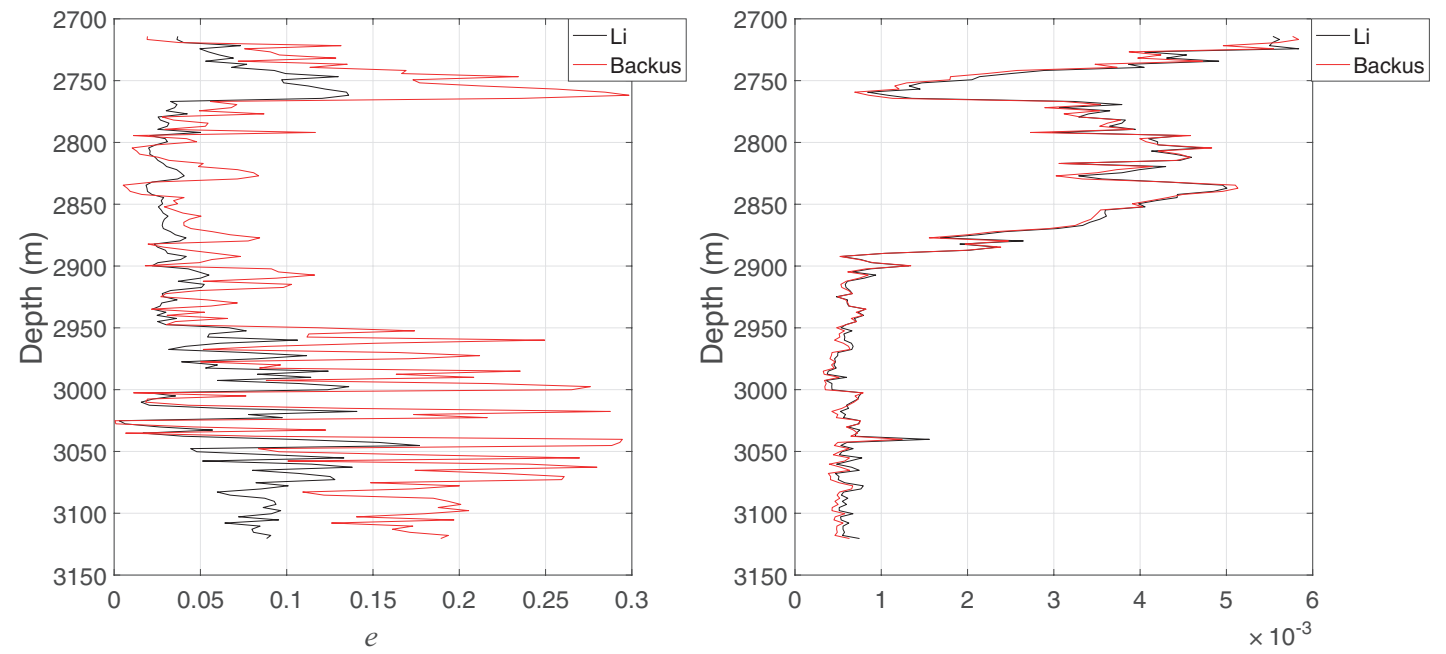

Figure 11 - Fracture density and aspect ratio logs for the well D4H.

and around $20 \%$ only on Not formation of well B4AH, while it does not exceed $1 \%$ on most part of the profiles. Therefore, we can infer that these fractures are related to the layers that have shale in its composition.

Based on the analysis of the parameters $\varepsilon, \gamma$ and $\delta$, and the fracture density and aspect ratio, the anisotropic characteristics of the area are consistent with the different logs. It can be considered that the Not formation is a datum to correlate these characteristics. It suggests the possibility of calculate the anisotropic parameters for the remaining wells drilled on the region and interpolate the values to use them on seismic processing.

\section{CONCLUSIONS}

On this work, we quantified the anisotropy by calculating the Thomsen anisotropics parameters from the data of five wells located on an area from Norne Field (Norway), using two methodologies: Li (2006) and Backus (1962). These methodologies provide the necessary parameters to characterize a VTI depth dependent medium, based on vertical measurements usually available on modern well logging profiles (Liner \& Fei, 2006). Laboratory measurements are the most trustful way to determine the intrinsic anisotropy of a rock. However, the 

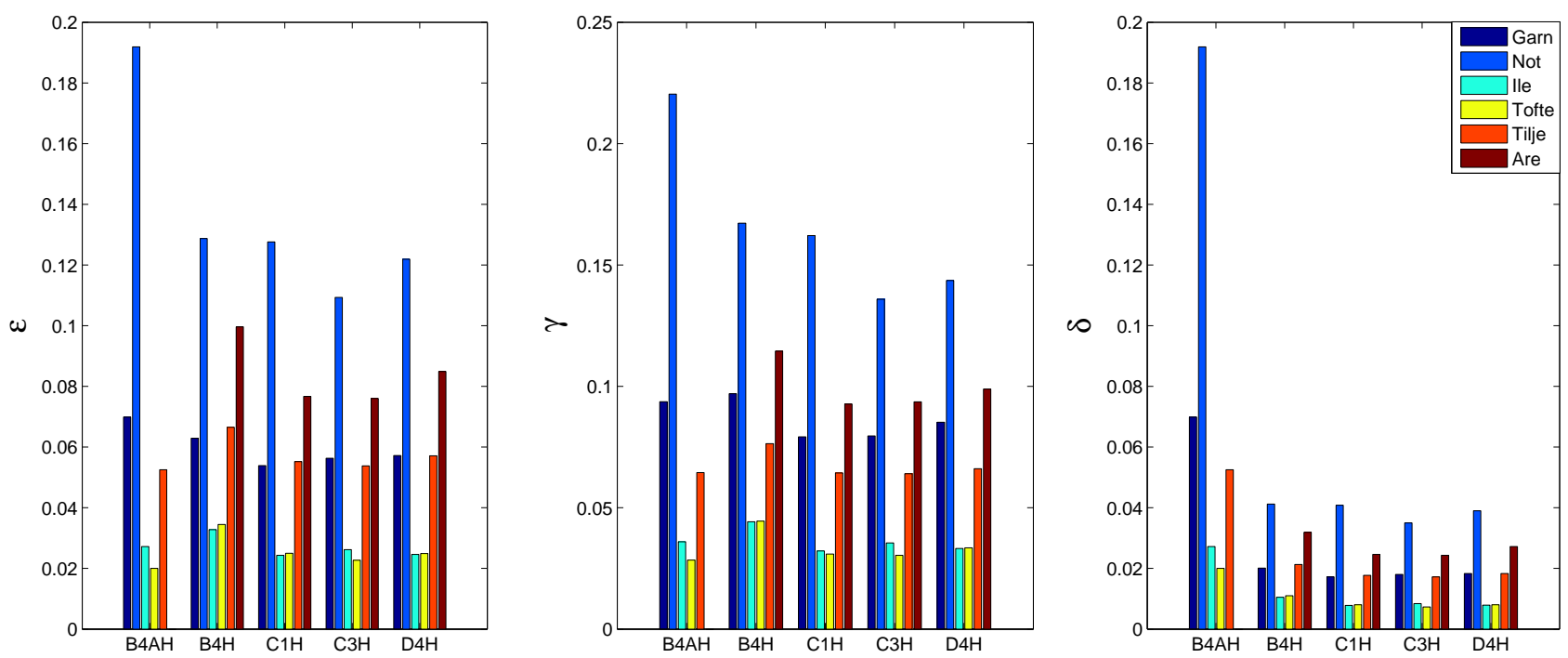

Figure 12 - Bar graph with the mean values of the anisotropic parameters of each formation present in all five studied wells.
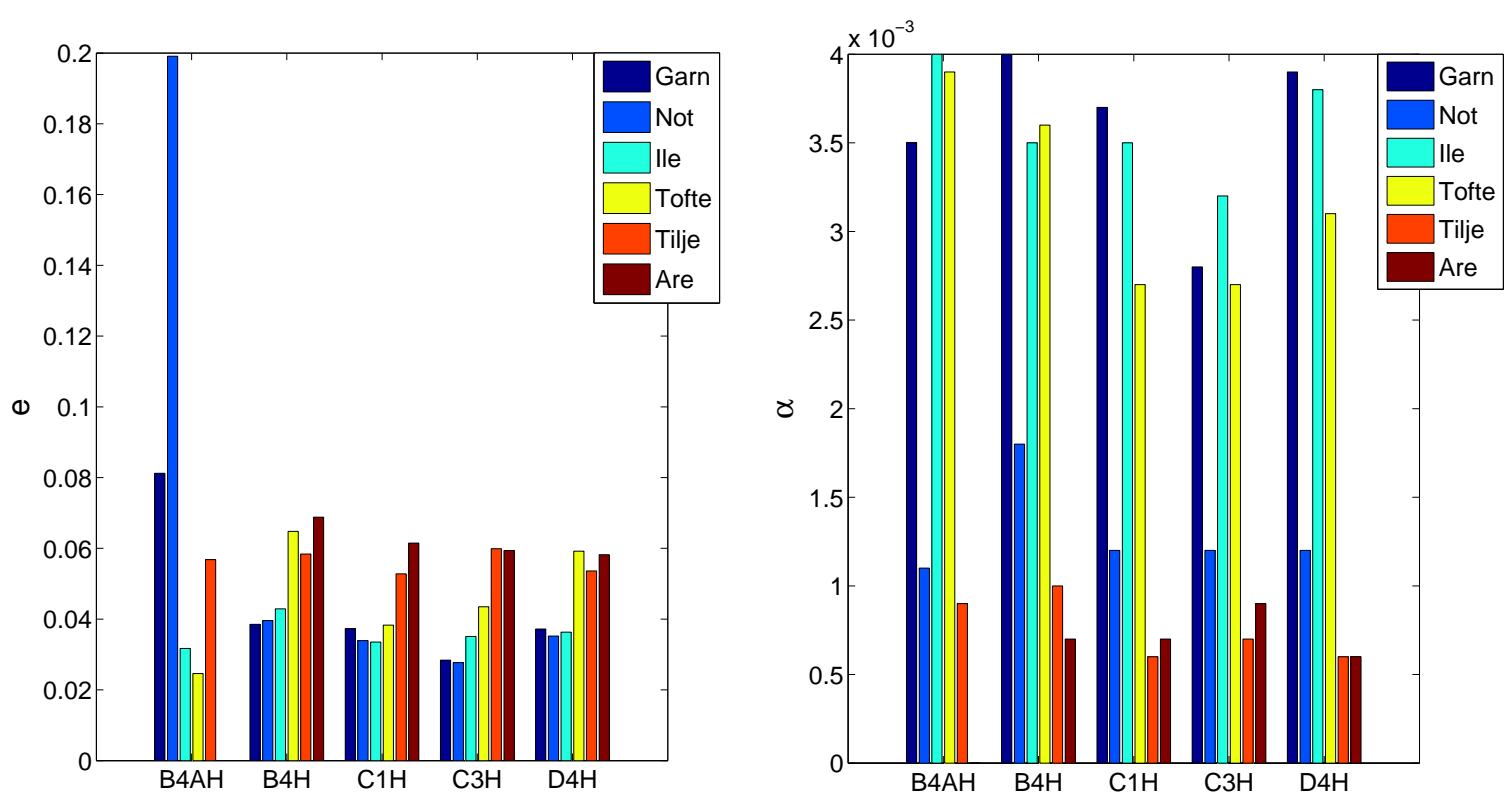

Figure 13 - Bar graph with the average values of fracture density and aspect ratio of each formation present in all five studied wells.

formulations that uses well datum may provide this information qualitatively.

Both methodologies showed satisfactory results, considering that they show very different ways to calculate the anisotropic parameters to obtain the elastic stiffness coefficients. Li (2006) considers the elastic waves propagation on quartz minerals while Backus (1962) does not require this detail.
However, in this study, to calculate the elastic constants, it requires the initial values of the anisotropic constants. Although the geologic formations have different compositions of quartz, and the initial values of anisotropic parameters have been originated from a close region, the results are satisfactory utilizing these methodologies. Thus, if the initial values of the parameters $\varepsilon, \gamma$ and $\delta$ are unknown, it is possible to enter with these values 
by Li (2006) method and calculate the coefficients $C_{i j}$ using the Backus average. The fracture density can be easily calculated once the stiffness coefficients are known. To calculate the aspect ratio, it is also necessary to know the water saturation.

The anisotropic parameters profiles calculated for the five wells studied in Norne Field, shows that the stratigraphic section of this region presents a weak anisotropic display, with the exception of some local points that get higher than 0.2 for $\varepsilon$ and $\gamma$. The values of parameter $\delta$ are low, getting lower than 0.05 . Experimental data for the correspondence of these results are not available. This test is fundamental for a more accurate analysis of the results obtained from both methodologies.

\section{REFERENCES}

BACKUS GE. 1962. Long-wave elastic anisotropy produced by horizontal layering. Journal of Geophysical Research, 67(11): 4427-4440. doi: 10.1029/JZ067i011p04427.

DOUMA J. 1988. The Effect of the Aspect Ratio on Crack-Induced Anisotropy. Geophysical Prospecting, 36(6): 614-632. doi: 10.1111/j. 1365-2478.1988.tb02183.x.

GUREVICH B. 1999. Elastic properties of saturated porous rocks with aligned fractures. Journal of Applied Geophysics, 54(3-4): 203-218. doi: 10.1016/j.jappgeo.2002.11.002.

IKELLE L \& AMUNDSEN L. 2005. Introduction to petroleum seismology. Investigations in Geophysics. n. 12. Tulsa, OK. Society of Exploration Geophysicists. 679 pp.

JOHNSTON JE \& CHRISTENSEN NI. 1995. Seismic anisotropy of shales. Journal of Geophysical Research, 100(B4): 5991-6003.

KUMAR D. 2013. Applying Backus averaging for deriving seismic anisotropy of a long-wavelength equivalent medium from well-log data. Journal of Geophysics and Engineering, 10(5): 055001 (15 pp.). doi: 10.1088/1742-2132/10/5/055001.
LARIONOV VV. 1969. Borehole radiometry. Nedra, Moscow. 230 pp.

LI Y. 2006. An empirical method for estimation of anisotropic parameters in clastic rocks. The Leading Edge, 25(6): 706-711. doi: 10.1190/1. 2210052.

LINER CL \& FEI TW. 2006. Layer-induced seismic anisotropy from full-wave sonic logs: Theory, application, and validation. Geophysics, 71(6): D183-D190. doi: 10.1190/1.2356997.

MAVKO G, MUKERJI T \& DVORKIN J. 2009. The rock physics handbook: tools for seismic analysis of porous media. 2nd ed., Cambridge, UK; New York: Cambridge University Press. 503 pp.

NERY GG. 2013. Perfilagem geofísica em poço aberto: fundamentos básicos com ênfase em petróleo. Sociedade Brasileira de Geofísica (SBGf) \& INCT-GP Brazil. 222 pp.

OUGIER-SIMONIN A, SAROUT J \& GUÉGUEN Y. 2009. A simplified model of effective elasticity for anisotropic shales. Geophysics, 74(3): D57-D63. doi: 10.1190/1.3096616.

SCHOENBERG M \& DOUMA J. 1988. Elastic wave propagation in media with parallel fractures and aligned cracks. Geophysical Prospecting, 36(6): 571-590. doi: 10.1111/j.1365-2478.1988.tb02181.x.

SHEARER PM. 2009. Introduction to seismology. 2nd ed., Cambridge: Cambridge University Press. 391 pp.

STATOIL. 2001. Norne field reservoir management plan. Technical Report $\mathrm{PL}-128$.

THOMSEN L. 1986. Weak elastic anisotropy. Geophysics, 51(10): 1954-1966. doi: 10.1190/1.1442051.

ZHU P, WANG J, YU W \& ZHU G. 2004. Inverting reservoir crack density from P-wave AVOA data. Journal of Geophysics and Engineering, 1(2): 168-175. doi: 10.1088/1742-2132/1/2/010. 